\title{
Applications of nanotechnology for melanoma treatment, diagnosis, and theranostics
}

\author{
This article was published in the following Dove Press journal: \\ International Journal of Nanomedicine \\ 23 July 2013 \\ Number of times this article has been viewed
}

\section{Jiezhong Chen ${ }^{1,2}$ \\ Renfu Shao ${ }^{3}$ \\ Xu Dong Zhang ${ }^{4}$ \\ Chen Chen'}

'School of Biomedical Sciences, University of Queensland, Brisbane, QLD, Australia; ${ }^{2}$ Faculty of Science, Medicine and Health, University of Wollongong, Wollongong, NSW, Australia; ${ }^{3}$ GeneCology Research Centre, School of Science, Education and Engineering, University of the Sunshine Coast, Maroochydore, QLD, Australia; ${ }^{4}$ School of Medicine and Public Health, University of Newcastle, Newcastle, NSW, Australia

Correspondence: Jiezhong Chen School of Biomedical Sciences, University of Queensland, St Lucia Campus, Brisbane, QLD 4072, Australia Tel +6I 733653856

Fax +6I 733652398

Email j.chen4@uq.edu.au
Abstract: Melanoma is the most aggressive type of skin cancer and has very high rates of mortality. An early stage melanoma can be surgically removed, with a survival rate of $99 \%$. However, metastasized melanoma is difficult to cure. The 5-year survival rates for patients with metastasized melanoma are still below 20\%. Metastasized melanoma is currently treated by chemotherapy, targeted therapy, immunotherapy and radiotherapy. The outcome of most of the current therapies is far from optimistic. Although melanoma patients with a mutation in the oncogene $v$-Raf murine sarcoma viral oncogene homolog B1 (BRAF) have an initially higher positive response rate to targeted therapy, the majority develop acquired drug resistance after 6 months of the therapy. To increase treatment efficacy, early diagnosis, more potent pharmacological agents, and more effective delivery systems are urgently needed. Nanotechnology has been extensively studied for melanoma treatment and diagnosis, to decrease drug resistance, increase therapeutic efficacy, and reduce side effects. In this review, we summarize the recent progress on the development of various nanoparticles for melanoma treatment and diagnosis. Several common nanoparticles, including liposome, polymersomes, dendrimers, carbon-based nanoparticles, and human albumin, have been used to deliver chemotherapeutic agents, and small interfering ribonucleic acids (siRNAs) against signaling molecules have also been tested for the treatment of melanoma. Indeed, several nanoparticle-delivered drugs have been approved by the US Food and Drug Administration and are currently in clinical trials. The application of nanoparticles could produce side effects, which will need to be reduced so that nanoparticle-delivered drugs can be safely applied in the clinical setting.

Keywords: metastasis, early detection, nanoparticle-delivered, PI3K/Akt

\section{Introduction}

Melanoma, originated from melanocytes, is the most aggressive type of skin cancer. ${ }^{1,2}$ Although melanoma represents only a very small proportion of skin cancer incidence, it accounts for the vast majority of skin cancer deaths. ${ }^{3}$ For example, there were more than 2 million new cases of skin cancer in USA in 2012, and among them only 75,000 (3.75\%) cases were melanoma. ${ }^{4}$ However, melanoma accounts for 9000 (75\%) deaths among the total 12,000 deaths caused by skin cancer in 2012. An early-stage melanoma that has not spread or metastasized to other organs can be removed by surgery, with high survival rates. It has been reported that the cure rate for those patients with removable melanoma reached 97\%-99.8\% after chemosurgery. ${ }^{5}$ However, metastasized irremovable melanoma needs to be treated by other standard therapies, such as chemotherapy, radiotherapy, targeted therapy, and immunotherapy. ${ }^{6,7}$ Unfortunately, treatment outcomes 
are not satisfactory and patients' responses to most of these therapies are very poor. ${ }^{8}$

At present, the most common drug used for the treatment of melanoma is dacarbazine (DTIC), which is a US Food and Drug Administration (FDA)-approved, first-line treatment for patients with wild-type melanomas. ${ }^{9}$ Although in vitro experiments showed that DTIC produced cytotoxicity in many melanoma cell lines, the response to DTIC was only $5 \%-10 \%$ when used alone. ${ }^{10}$ The use of targeted therapy against mutated oncogene $v$-Raf murine sarcoma viral oncogene homolog B1 (BRAF) showed a dramatically increased response, reaching $80 \%{ }^{11,12}$ Unfortunately, most patients will have acquired drug resistance to BRAF inhibitors after 6 months of treatment, resulting in loss of clinical efficacy. The median survival time of patients with metastasized melanoma is only 6-10 months, and the 5-year survival rate is less than $20 \%{ }^{13-15}$ Therefore, improved treatment efficiency is urgently needed for melanoma. To achieve this, improvement in the diagnosis and treatment is required. Early detection of melanoma can lead to surgical removal before metastasis. Identification of the involved gene mutations and understanding of the dysregulation in the key signaling pathways can help in the design of proper therapeutic regimes. Successful treatment will also rely on the discovery of specific, more potent pharmacological agents and efficient delivery systems.

Nanotechnology involves the design, development, characterization, and application of materials in nanoscale and has been extensively studied for medical applications. ${ }^{16}$ Applications of nanotechnology in the diagnosis and treatment of melanoma have been studied extensively and have advanced the study of melanoma in several aspects. ${ }^{17,18}$ Nanoparticles provide an effective drug delivery system, allowing anticancer drugs to reach the cancer site specifically and thus greatly improving treatment efficacy. Nanotechnology also has helped in diagnosis, by allowing imaging agents to be packed into nanoparticles that reach the cancer. In this review, we summarize the recent progress in the application of nanotechnology in the diagnosis and treatment of melanoma.

\section{Common nanoparticles used in melanoma treatment}

Rapid progress in understanding the biology of cancer cells has been made in the past decade. However, the treatment outcomes of cancers have not changed much. The failure of anticancer therapies is considered to be due to the side effects of most anticancer drugs, low concentrations of the drugs at the tumor site, and the development of drug resistance. ${ }^{19,20}$ Nanoparticles have been studied extensively for drug delivery, to increase anticancer treatment efficacy. Compared with conventional drug delivery approaches, nanoparticle-mediated delivery of anticancer drugs brings several remarkable advantages. First, drugs delivered by nanoparticles may have a longer biological life, due to packaging protection, and may be concentrated in the site of cancer due to enhanced permeability and retention (EPR) at cancer sites. ${ }^{21}$ EPR is caused by the leakiness of tumor vasculature as well as poor lymphatic drainage. ${ }^{22}$ Therefore, nanotechnology increases treatment efficacy and decreases side effects. For example, Doxil ${ }^{\circledR}$ (Janssen Biotech, Horsham, PA, USA), which is doxorubicin (Dox) formulated in liposomes containing polyethylene glycol (PEG), has a 100-fold longer circulation half-life and sevenfold lower cardiocytotoxicity than has free Dox. ${ }^{22}$ Second, a nanoparticle can contain multiple drugs and thus will facilitate combination therapy. It is known that the combination of chemotherapy with immunotherapy or targeted therapy produces much more effective treatment outcomes. ${ }^{16}$ Third, nanoparticles can protect drugs made of fragile small interfering ribonucleic acid (siRNA) or proteins, from biochemical degradation in the human body. This is due to the stealth-like features of nanoparticles. ${ }^{23}$ Fourth, nanoparticles produce a constant release of delivered drugs. Furthermore, nanoparticles can be designed to have multiple functions, such as targeting to cancer cells and producing image contrast. ${ }^{24}$ Many nanoparticles have been studied for the treatment of melanoma, including liposomes, dendrimers, polymersomes, carbon-based nanoparticles, inorganic nanoparticles, and protein-based nanoparticles (Table 1). ${ }^{16,25,26}$

A liposome is a sphere consisting of a lipid bilayer that contains aqueous core for hydrophilic drugs. ${ }^{24}$ Hydrophobic drugs can be contained between the two layers. Liposome was invented more than 50 years ago and was the first nanoparticle used in medicine. ${ }^{27}$ Liposome is prepared by sonicating a lipid, with a process involving emulsification. Homogeneous nanosized liposomes can be achieved by filtering through a $0.2 \mu \mathrm{M}$ membrane. ${ }^{28}$ Furthermore specific ligands against tumor antigens can be attached to the liposome surface so that the nanoparticles can target cancer cells specifically. ${ }^{29,30}$ Liposomes have been used to carry chemotherapeutic drugs, immunocytokines, and siRNA, to increase treatment efficacy for melanoma. ${ }^{16}$ Similar structural nanoparticles have been designed, such as the cubosome and niosome, which consist of lipids. ${ }^{24}$ 
Table I Characteristics and side effects of common nanoparticles used in the study of melanoma treatment

\begin{tabular}{|c|c|c|c|c|c|}
\hline Nanoparticle & $\begin{array}{l}\text { Sample drugs delivered } \\
\text { for melanoma }\end{array}$ & Clinical use & Characteristics & Side effects & Possible solutions \\
\hline Liposomes & $\begin{array}{l}\text { Cisplatin } \\
\text { Vincristine } \\
\text { Doxorubicin }\end{array}$ & Doxil & $\begin{array}{l}\text { High biocompatibility } \\
\text { High biodegradability } \\
\text { High cell uptake rates } \\
\text { Low drug encapsulation } \\
\text { efficacy } \\
\text { High cost }\end{array}$ & $\begin{array}{l}\text { Hand-foot syndrome (skin } \\
\text { rash, swelling, redness, pain) } \\
\text { Toxicity to normal cells } \\
\text { due to positive charge }\end{array}$ & $\begin{array}{l}\text { Increase drug loading } \\
\text { to reduce liposomes } \\
\text { to be used } \\
\text { Use of natural lipids }\end{array}$ \\
\hline Dendrimers & $\begin{array}{l}\text { Doxorubicin } \\
\text { Cisplatin } \\
\text { Paclitaxel } \\
\text { Vincristine }\end{array}$ & $\begin{array}{l}\text { Not yet } \\
\text { available }\end{array}$ & $\begin{array}{l}\text { High stability } \\
\text { High solubility } \\
\text { High drug encapsulation } \\
\text { Uniform size } \\
\text { Low biodegradation }\end{array}$ & $\begin{array}{l}\text { Surface charge } \\
\text { Accumulation in kidney } \\
\text { and reticuloendothelium }\end{array}$ & $\begin{array}{l}\text { Attach anionic polymer } \\
\text { Control the size }\end{array}$ \\
\hline Polymersomes & $\begin{array}{l}\text { Doxorubicin } \\
\text { Paclitaxel } \\
\text { Cyclodextrin }\end{array}$ & $\begin{array}{l}\text { Not yet } \\
\text { available }\end{array}$ & $\begin{array}{l}\text { High biodegradability } \\
\text { Controlled release } \\
\text { Not uniform size }\end{array}$ & $\begin{array}{l}\text { Accumulation in kidney } \\
\text { and reticuloendothelium }\end{array}$ & Control the size \\
\hline $\begin{array}{l}\text { Carbon-based } \\
\text { nanoparticles }\end{array}$ & Doxorubicin & $\begin{array}{l}\text { Not yet } \\
\text { available }\end{array}$ & $\begin{array}{l}\text { High biocompatibility } \\
\text { High photostability } \\
\text { Small size } \\
\text { Not biodegradable }\end{array}$ & $\begin{array}{l}\text { Inflammation } \\
\text { ROS production }\end{array}$ & Adjust the size \\
\hline Human albumin & Paclitaxel & $\begin{array}{l}\text { Nab-paclitaxel } \\
\left(\text { Abraxane }^{\circledR}\right)\end{array}$ & $\begin{array}{l}\text { High solubility } \\
\text { High stability } \\
\text { Low toxicity }\end{array}$ & $\begin{array}{l}\text { Side effects related with } \\
\text { delivered drugs }\end{array}$ & $\begin{array}{l}\text { Reduce dosage for a } \\
\text { specific drug through } \\
\text { combination therapies }\end{array}$ \\
\hline
\end{tabular}

Abbreviations: nab-paclitaxel, nanoparticle albumin bound-paclitaxel; ROS, reactive oxygen species.

Dendrimers are synthetic polymers with branches that form a tree-like structure, which encapsulate drugs within their internal cavities. ${ }^{31}$ Recently, tecto(dendrimers) have been made, which introduce covalent linkages between dendrimer building blocks to achieve higher architectural structures. ${ }^{32}$ Schilrreff et al made a dendrimer by using amine-terminated polyamidoamine (PAMAM) generation 5 (G5) as a core and carboxyl-terminated PAMAM G2.5 as the shell and demonstrated it was toxic to the melanoma cell line SK-Mel-28, but not to normal keratinocytes. ${ }^{32}$ The immunogenicity of dendrimers may cause unwanted systemic immune reaction, which may limit their therapeutic application.

Polymersomes are composed of amphiphilic block copolymers, such as polylactic acid and poly( $\varepsilon$-caprolactone), formulated to become nanoparticles. ${ }^{33}$ Polymersomes can encapsulate either hydrophilic or hydrophobic drugs. ${ }^{34}$ They are more stable and less permeable to small water-soluble molecules than are liposomes. ${ }^{35}$ Their surface can also be attached with ligands for targeting cells and controllable release. Polymersomes have been used to deliver Dox for treating melanoma and demonstrated to be preferentially taken up by melanoma cells. ${ }^{36}$ The nanoparticles markedly reduced tumor growth in a melanoma xenograft model.

Carbon-based nanoparticles were first made in 1985 and known as fullerenes, which were composed of 60 carbon atoms. ${ }^{37}$ In 1991, a carbon nanotube was established. Recently, nanodiamonds were used to deliver drugs against melanoma. ${ }^{16}$ Carbon-based nanoparticles have been shown to increase the efficacy of chemotherapy in melanoma cells. ${ }^{16,38}$ Chaudhuri et a ${ }^{138}$ showed that a singlewalled carbon nanotube loaded with Dox induced melanoma cell death in a dose-dependent fashion in vitro and abrogated tumor growth in a xenograft melanoma model.

Inorganic nanoparticles made from materials such as silica and aluminum have also been applied in melanoma therapy. Silica can be made multiporous (which is then called mesoporous silica) to carry more drugs than as a simple sphere. ${ }^{39}$ A layered double hydroxide nanoparticle is made by layering a hydroxyl (-OH) group on inorganic materials, to carry drugs. ${ }^{40}$ This has been shown to increase immune response to a deoxyribonucleic acid (DNA) vaccine in a melanoma mouse model ${ }^{41}$ At present, the capability of layered double hydroxide to carry enough small molecular drug is still a major problem.

Human albumin has also been used to make nanoparticles for the treatment of melanoma. ${ }^{42}$ An albumin-based nanoparticle, Abraxane ${ }^{\circledR}$ (Abraxis Bioscience, Summit, NJ, USA) (also known as ABI-007 or nanoparticle albumin bound [nab]-paclitaxel [PTX]) has been approved by the FDA for clinical use. PTX is non-water soluble, and nonionic surfactant, such as Cremophor ${ }^{\circledR}$ EL (BASF Corp), is used to make a suspension. ${ }^{43}$ This increases side effects, including 
acute hypersensitivity reactions, anemia, and cardiovascular events. ${ }^{43}$ Albumin has been used to conjugate PTX with Cremophor, to reduce these side effects. Clinical trials have shown that Abraxane was better tolerated and more effective against melanoma than was free PTX ${ }^{44,45}$ However, a recent report showed that poly(gamma-L-glutamylglutamine)-PTX was more effective in reducing the growth of xenografted B16 melanoma cells than was Abraxane and had less side effects. $^{46}$

\section{The applications of nanotechnology in the conventional therapies of melanoma}

Nanotechnology has been applied to most conventional therapies for melanoma. It has been demonstrated that the nanodelivery of drugs for chemotherapy, targeted therapy, immunotherapy, and photodynamic therapy has greatly increased treatment efficacy. ${ }^{16,25,26}$

\section{Chemotherapy}

Chemotherapy is the most common conventional therapy for melanoma. Chemotherapeutic agents kill both malignant and normal cells that are in division. ${ }^{47}$ Therefore, they are very toxic, and this limits the dosage to be used. The common chemotherapeutic agents used in melanoma are DTIC, vinblastine, and temozolomide. The response rates, however, are very low. It has been reported that the response to DTIC, vinblastine, and temozolomide was 7\%, 9.5\%, and $28 \%$, respectively in a clinical trial with 64 patients. $^{7}$ Nanoparticles have been used to deliver chemotherapeutic agents and demonstrated to increase treatment efficacy and reduce side effects. Zhang et al showed that delivering the chemotherapeutic agent Dox by gold nanoparticles was very effective against a melanoma cell line. ${ }^{48}$ Lo Prete et al applied a cholesterol-rich nanoemulsion (termed "LDE") to deliver etoposide in a mouse model of melanoma. ${ }^{49}$ It decreased side effects, increasing maximum tolerated dose fivefold, and increased the inhibition of tumor growth by concentrating etoposide at the tumor site (a fourfold higher concentration in tumor than with free etoposide). Ndinguri et al packed Dox in a nanoparticle with additional antibody against CD44, to specifically target malignant cells. ${ }^{50}$ The nanoparticle reduced the tumor size by $60 \%$ compared with untreated tumor.

Nab-PTX (Abraxane) has been approved by the FDA for the treatment of breast cancer. Hersh et al reported a Phase II clinical trial using nab-PTX (Abraxane) in both previously treated and untreated melanoma patients. ${ }^{45}$ The response rates were $2.7 \%$ and $21.6 \%$, respectively. In the study,
$22 \%$ chemotherapy-naive patients discontinued treatment due to grade 3 or 4 neuropathy, alopecia, neutropenia, and fatigue. Kottschade et $\mathrm{l}^{51}$ conducted a Phase II clinical trial using nab-PTX and carboplatin in advanced melanoma, in 41 chemotherapy-naive and 35 previously-treated melanoma patients. The response rate was $25.6 \%$ in the chemotherapynaive cohort and was $8.8 \%$ in the previously-treated cohort. The severe side effects were neutropenia, thrombocytopenia, neurosensory problems, fatigue, nausea, and vomiting. In another clinical trial, Kottschade et $\mathrm{al}^{52}$ showed vascular endothelial growth factor (VEGF) antibody increased the effect of nab-PTX. Ott et al showed that the combination of a B cell lymphoma protein $(\mathrm{Bcl})-2$ antisense oligonucleotide, temozolomide, and nab-PTX produced a response of $40.6 \%{ }^{53}$ Similar side effects to that revealed in Kottschade et al's study were also reported.

\section{Targeted therapy}

Intracellular signaling pathways play a key role in the carcinogenesis and prognosis of many cancers, including melanoma, and many inhibitors have been developed for the treatment of cancer (Table 2). ${ }^{54,55}$ These pathways are activated either by genetic defects or environmental factors. ${ }^{56}$ Obesity is a common disease that is characterized by dysregulated energy balance and metabolic disturbance. ${ }^{57}$ It can increase cancer incidence and results in poorer prognosis through the activation of multiple signal pathways, including mitogenactivated protein kinase (MAPK), phosphoinositide 3-kinase $(\mathrm{PI} 3 \mathrm{~K})$, and signal transducer and activator of transcription 3 (STAT3). ${ }^{54,58-60}$ The MAPK pathway is a major pathway in melanoma. It has been studied extensively in melanoma, and

Table 2 Common inhibitors of the PMAPK and PI3K/Akt pathways

\begin{tabular}{|c|c|c|}
\hline $\begin{array}{l}\text { Signaling } \\
\text { molecule }\end{array}$ & Inhibitors & References \\
\hline RTK & Imatinib, dasatinib, sorafenib & Inamdar ${ }^{55}$ \\
\hline Ras & $\begin{array}{l}\text { Tipifarnib, RII5777, BMS-2 I4662, } \\
\text { L-778I } 23\end{array}$ & Inamdar 55 \\
\hline Raf & Sorafenib, PLX4032, XL28I, RAF-265 & Inamdar 55 \\
\hline Mek & $\begin{array}{l}\text { AZD6244, U0I26, PD032590I, Cl-I040, } \\
\text { XL5I8, AZD8330, ARRY-I62, ARRY-300, } \\
\text { perifosine, erucyl-phosphocholine }\end{array}$ & $\begin{array}{l}\text { Chen }^{54} \\
\text { Inamdar }\end{array}$ \\
\hline ERK & DHMEQ & Inamdar ${ }^{55}$ \\
\hline Akt & Ly294002, Bez235, PII03 & Inamdar 54,55 \\
\hline mTOR & Rapamycin, Bez235, PII03 & Inamdar 54,55 \\
\hline NF-kB & Curcumin, plumbagin & Inamdar 55 \\
\hline
\end{tabular}

Abbreviations: Akt, protein kinase B; ERK, extracellular signal-regulated kinase; $M E K$, mitogen-activated protein kinase; mTOR, mammalian target of rapamycin; NF-kB, nuclear factor-kappaB; PI3K, phosphoinositide 3-kinase; PMAPK, phosphorylated mitogen-activated protein kinase; Raf, rapidly accelerated fibrosarcoma; Ras, rat sarcoma protein (subfamily of small GTPases); RTK, receptor tyrosine kinase. 
many inhibitors have been developed to inhibit this pathway for treatment. Activation of the MAPK pathway in melanoma has been shown to be caused by the activation of mutations in its components; the mutation rate is $50 \%-70 \%$ for $B R A F$, $15 \%-30 \%$ for $N R A S, 2 \%$ for $K R A S$ and $1 \%$ for $H R A S .{ }^{61-63}$ The PI3K/protein kinase B (Akt) pathway can synergistically affect the MAPK pathway to promote the development of melanoma. ${ }^{64}$ The signaling pathways of MAPK and PI3K/ Akt and their crosstalk are shown in Figure 1. Both pathways regulate a broad range of target proteins. ${ }^{58,65}$ A common survival pathway downstream of both MAPK and PI3K/Akt is the mitochondrial apoptosis signal pathway that includes the Bcl-2 family of proteins, including both proapoptotic and antiapoptotic signals. Furthermore, inhibition of both the MAPK and PI3K/Akt pathways has been shown to have a synergistic effect in the treatment of melanoma. ${ }^{66}$

Nanotechnology has been used to deliver certain inhibitors of the MAPK pathway. ${ }^{55,67}$ A chitosan nanoparticle was used to deliver the downstream target protein VEGF siRNA and was demonstrated to improve the therapeutic effect. ${ }^{68}$ Yin et al used functional graphene oxide to deliver a plasmid-based STAT3 siRNA and showed significantly reduced xenografted tumor growth. ${ }^{69}$ Indeed, STAT3 is considered as a key mediator in melanoma which promotes brain metastasis. ${ }^{70}$ Inhibition of phosphorylated STAT3 has been shown to increase efficacy of tumor necrosis factor (TNF)-alpha for melanoma. ${ }^{71}$ A nanoparticle has also been designed to carry siRNA against the oncogene $c-M y c$ to target melanoma cells B16F10 and demonstrated effectiveness against melanoma. ${ }^{72}$ Tran et al prepared a nanoparticle to contain both siRNAs against BRAF and Akt3 which markedly increased the anticancer effect. ${ }^{73}$

\section{Targeting the mitochondrial pathway}

As discussed above, a major downstream mediator of PI3K/ Akt and MAPK is the mitochondrial apoptotic pathway. The pathway is regulated by proapoptotic proteins and antiapoptotic proteins. The former includes Bak, Bax, Bid, Bim, Bcl-associated death promoter (BAD), Noxa, and PUMA. The latter includes Bcl-2, Bcl-xL, Bcl-w, Mcl-1, and A1. ${ }^{74}$ Both PI3 K and MAPK can increase antiapoptotic

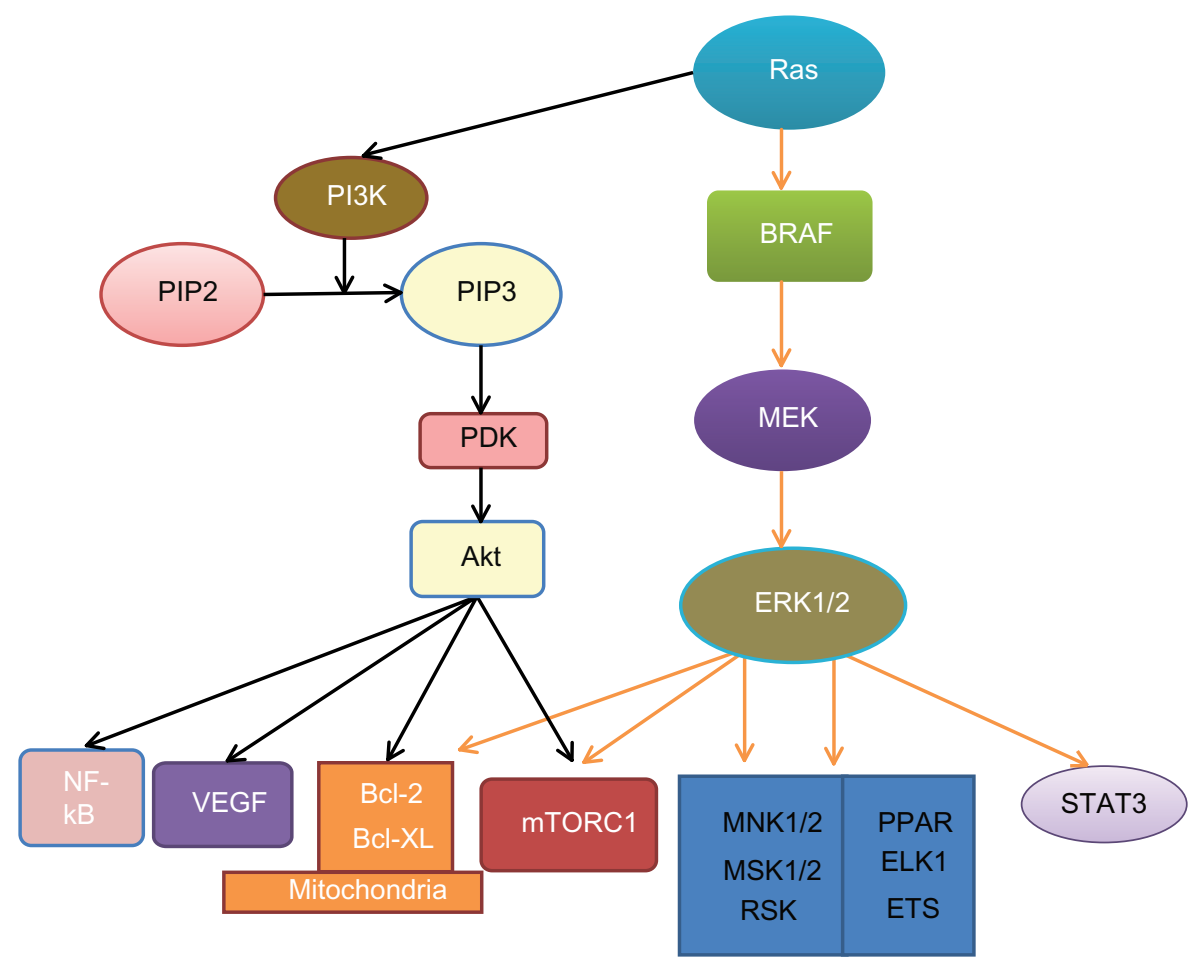

Figure I Signaling pathways in melanoma.

Notes: Oncoprotein Ras activates both the MAPK and PI3K/Akt survival pathways. Ras can stimulate BRAF activity, which in turn, activates MEK and ERKI/2. Ras also activates PI3K, which catalyzes PIP2 into PIP3. PIP3 increases Akt activity via PDK. Both Akt and ERKI/2 act on the mitochondrial apoptosis signaling pathway and mTORCI. Akt also targets VEGF and NF-kB. ERKI/2 can also activate STAT3 and other transcriptional factors, such as MNKI/2, MSKI/2, ELK, ETS, RSK, PPAR, ELKI, and ETS.

Abbreviations: Akt, protein kinase B; Bcl-2, B cell lymphoma protein 2; Bcl-XL, B cell lymphoma protein extra large; BRAF, v-Raf murine sarcoma viral oncogene homolog $\mathrm{BI}$; ELKI, member of the E-twenty-six transcriptional family; ERK, extracellular signal-regulated kinase; ETS, E-twenty-six (transcriptional family); MAPK, mitogen-activated protein kinase; MEK, MAPK kinase; MNKI, 2, MAPK-interacting kinases I, 2; MSKI, 2, stress-activated kinases I, 2; mTORCI, mammalian target of rapamycin complex I; NF-kB, nuclear factor-kappaB; PI3K, phosphoinositide 3-kinase; PIP2, phosphatidylinositol-4,5-bisphosphate; PIP3, phosphatidylinositol-3,4,5-trisphosphate; PDK, putative 3-phosphoinositide-dependent kinase; PPAR, peroxisome-proliferator-activated receptor; Ras, rat sarcoma protein (subfamily of small GTPases); RSK, $90-k D a$ ribosomal S6 protein kinase; STAT3, signal transducer and activator of transcription 3; VEGF, vascular endothelial growth factor. 
protein expression and decrease proapoptotic protein expression and thus increase the ratio of antiapoptotic proteins/proapoptotic proteins. This plays a key role in melanoma initiation, maintenance, and drug resistance. ${ }^{75}$ Reversal of this ratio, either by inhibition of antiapoptotic proteins or overexpressing proapoptotic proteins, has been used for the treatment of melanoma. For example, inhibition of Bcl-2 by ABT-737 caused melanoma cell apoptosis. ${ }^{76}$

Nanotechnology has been found to increase the therapeutic effect of Bcl-2 inhibition. In nude mice, oblimersen (an antisense oligonucleotide against Bcl-2) decreased xenografted melanoma growth. ${ }^{77}$ The dual application of oblimersen with DTIC in patients in a Phase III clinical trial resulted in increased effectiveness compared with DTIC alone (9 vs 7.8 months, respectively, for overall survival; 2.6 vs 1.6 months, respectively, for progression-free survival; $13.5 \%$ vs $7.5 \%$, respectively, for overall response; $2.8 \%$ vs $0.8 \%$, respectively, for complete response; and $7.3 \%$ vs $3.6 \%$, respectively for durable response). ${ }^{78} \mathrm{~A}$ nanoparticle was made to carry Bcl-2 siRNA (as well as Myc and VEGF) for the treatment of melanoma. ${ }^{79}$ It was shown that this resulted in $\mathrm{Bcl}-2$ reduction in both messenger ribonucleic acid (mRNA) and protein levels. This increased anticancer effects both in vitro and in vivo. Oblimersen has been used in Phase I clinical trial in combination with temozolomide and nab-PTX and proved more effective in patients with advanced melanoma. ${ }^{53}$

\section{Immunotherapy}

Immunotherapy is used to improve the immune response of patients with melanoma, to increase the clearance of cancer cells, especially those already damaged by chemotherapy or targeted therapy. Without immunotherapy to clear damaged cancer cells, the efficacy of treatment would not be achieved, as these damaged cells may self-repair and become more malignant. In melanoma, several immunocytokines have been shown to have initial effects, but these effects are limited by side effects. ${ }^{80}$ The commonly used immunostimulators in melanoma are interleukin (IL)-2, interferon (IFN)-alpha, ipilimumab, and thymosin alpha $1 .^{81-84} \mathrm{IL}-2$ has been reported to increase remission time but that high-dose IL-2 may cause acute side effects and possibly death. ${ }^{80,83}$

Nanoparticles have been used to deliver immunotherapy drugs, to reduce side effects. ${ }^{85,86}$ Yao et al prepared a novel nanoparticle containing IL-2 and tested it in a mouse model with xenografted melanoma. ${ }^{87}$ The nanoparticle was made from low-molecular weight polyethylenimine (600 Da), which was linked to $\beta$-cyclodextrin, conjugated with folate, and further mixed with IL-2 plasmid. It was shown that the particle inhibited tumor growth and prolonged the survival of the melanoma-bearing mice. ${ }^{87} \mathrm{He}$ et al used a biodegradable polymer, poly(polycaprolactone), to make a nanoporous miniature device for local delivery of cytokine IFN-alpha and showed constant slow release of IFN-alpha. ${ }^{88}$ Speiser et al prepared a nanoparticle containing cytosinephosphodiester-guanine $(\mathrm{CpG})$-loaded virus-like particle carrying melanoma antigen recognized by $\mathrm{T}$ cells 1 (Mart-1) to target melanoma cells, and this nanoparticle produced a strong immune response against melanoma, including increased cytotoxic CD8 T-cell responses. ${ }^{89}$ Furthermore, two ligands have been loaded into a nanoparticle. For example a nanoparticle with both CD40 and Toll-like receptor (TLR) stimulators was used to increase dendritic cells (DCs) and CD8-T-cells. ${ }^{90}$ A nanoparticle combining TLR 7 and 9 ligands has also been demonstrated to exert a synergistic effect. ${ }^{91}$ A nanoparticle made from lipopolyplexes was used to deliver melanoma antigen mRNA. A mannosylated form of nanoparticle has been shown to increase the efficacy of transfection into DCs. ${ }^{86}$ In an animal model, mannosylated and histidylated lipopolyplexes showed a greater ability to reduce tumor growth than did the sugar-free form. A possible explanation is that these nanoparticles can be better taken up by DCs and thus induced more tumor-specific cytotoxic T lymphocytes. Therefore, it is clear that nanotechnology can be used to improve immunotherapy in melanoma.

\section{Photodynamic therapy (PDT)}

PDT is a therapy that applies nontoxic, light-sensitive compounds, which become toxic after light exposure. ${ }^{92}$ In PDT, a photosensitizer is administered and then excited by suitable irradiation, emitted from a light source, to generate single oxygen $\left({ }^{1} \mathrm{O}_{2}\right)$, superoxide anion radical $\left(\mathrm{O}_{2}^{-}\right)$, and hydroxyl radical $(\mathrm{OH})$ for therapy ${ }^{92}$ It has been demonstrated in a mouse model with xenografted melanoma that PDT induced significant apoptosis, necrosis, and tumor growth arrest and thus prolonged the survival time of the animals bearing melanoma. ${ }^{92}$

Camerin et al used nanoparticles to carry $\mathrm{Zn}[\mathrm{II}]-$ phthalocyanine disulfide $(\mathrm{C} 11 \mathrm{Pc})$ to test PDT treatment efficacy in a mouse model of xenograft melanoma. ${ }^{93}$ It was found that gold nanoparticle-associated $\mathrm{C} 11 \mathrm{Pc}$ had more effective treatment outcomes. The nanoparticle had greater accumulation than did free $\mathrm{C} 11 \mathrm{Pc}$, and the ratio of $\mathrm{C} 11 \mathrm{Pc}$ between melanoma and skin increased from 2.3 to 5.5. Electron microscopy showed that the C11Pc delivered by nanoparticles caused more damage in blood capillaries and 
endothelial cells than did the free $\mathrm{C} 11 \mathrm{Pc} .{ }^{93}$ In other work, a nanoparticle was used to deliver two photosensitizers, to increase therapeutic efficacy in melanoma. ${ }^{94}$

\section{Magnetite nanoparticles}

Sato et al designed a magnetite nanoparticle by conjugating N-propionyl-cysteaminylphenol with magnetite and used this in a B16F1 xenograft mouse model..$^{95}$ Electron microscopy demonstrated this particle appeared only in melanoma cells. It was shown that the melanoma cells were degraded after the application of an external alternating magnetic field to increase the temperature in the tumor to $43^{\circ} \mathrm{C}$. The nanoparticle had a 1.7 to 5.4 -fold greater effect than did the magnetite used alone. A recent study showed that curcumin further increased the efficacy of magnetite nanoparticles. ${ }^{96}$

\section{Inhibition of the drug detoxification system}

The accumulation of anticancer drugs in cancer cells is closely associated with anticancer effects. Drug resistance is often caused by activation of the cellular detoxification system, which includes the drug pump, permeability glycoprotein (P-gp), and the drug metabolism enzyme, cytochrome P450 (CYP). ${ }^{97,98}$ Both P-gp and CYP are regulated by several nuclear receptors, such as pregnane $\mathrm{X}$ receptor (PXR), farnesoid X receptor (FXR), and constitutive androstane receptor (CAR). Nanoparticle-delivered Dox or PTX has been shown to inhibit P-gp expression and has a much greater effect against melanoma that does free Dox and PTX. ${ }^{99}$ Further, siRNA against the mRNAs for these proteins has been carried by nanoparticles for the treatment of cancers. It has been shown in breast cancer that the inhibition of P-gp by nanoparticle-delivered Bcl-2, Myc, and PXR siRNAs produced a greater anticancer effect than did the inhibition of Bcl-2, Myc, and PXR by free siRNA. ${ }^{100}$ However, this has not been studied in melanoma and may warrant investigation.

\section{The application of nanotechnology for the diagnosis of melanoma}

The aim of initial diagnosis is to make a judgment about whether melanoma is present and at what developmental stage is the melanoma. An early diagnosis is critical to obtain high survival rates for melanoma patients. Beyond naked-eye examination and histological observation, many new technologies have been used to aid diagnosis, such as dermoscopy, total body photography, reflectance confocal microscopy, multispectral digital imaging analysis, and
RNA microarray. ${ }^{101,102}$ In metastasized melanoma, molecular signatures of the melanoma may be identified so that a proper treatment regime can be made. This is important, as the molecular alterations are associated with intracellular signaling pathway changes, clinical features, and responses to different treatment regimes. Molecular diagnosis could be included in the routine diagnosis for melanoma in the near future. ${ }^{103}$ More and more newly developed techniques are used in the molecular diagnosis of melanoma, such as tissue array, proteomics, and DNA sequencing. ${ }^{104}$ During the treatment of melanoma, judgment of efficacy is needed to assess whether the approach used is appropriate and whether there is any better way to increase the patient's response to treatment. This determination includes imaging tumor size and vascular structure. Nanotechnology has been proven to be a valuable tool to improve the diagnosis of melanoma.

Nanoparticle quantum dots (QDs) have been used for the early detection of melanoma, due to their photophysical properties, including exceptional brightness, size-tunable emission wavelength, broad excitation spectrum with narrow emission profile, and excellent photostability. ${ }^{105,106}$ QDs can be conjugated with cancer-specific molecules, such as folic acid or antibodies recognizing antigens overexpressed in cancer cells. ${ }^{107}$ Zheng et al used PEG-COOH capped highly fluorescent $\mathrm{CdSe} / \mathrm{ZnS}$ core/shell QDs conjugated with antibody against CD146 to detect CD146 overexpressed melanoma cells in cultured and fixed cells. ${ }^{108}$ Flow cytometry and confocal microscopy showed the positive cells to have high brightness, photostability, and specificity. Kim et al developed a coculture system containing both melanoma cells and normal melanocytes to test QDs conjugated with antibodies (ab732 or Ab733) against melanoma. ${ }^{106}$ It was shown that melanoma cells could be distinguished from melanocytes.

Melanoma is a heterogeneous disease. ${ }^{109}$ Each type may have different mechanisms with different gene mutations and the activation of different signaling pathways and thus, different responses to anticancer drugs. Therefore, it is necessary, for efficient treatment, to identify the molecular signatures for each melanoma patient, and to plan personalized treatment. ${ }^{110}$ For example, melanoma can be classified into one of two categories depending on whether a $B R A F$ mutation exists, as the BRAF inhibitor vemurafenib is only effective for those with a $B R A F$ mutation. Patients with the $B R A F$ mutation have as high as an $80 \%$ response to vemurafenib. ${ }^{11,112}$ Therefore, detection of a $B R A F$ mutation is of importance for the selection of treatment regimes. Nanotechnology has been used to improve the detection of 
$B R A F$ mutation. ${ }^{113}$ In an assay using microcantilever arrays, a $B R A F$-specific oligonucleotide probe was used to detect mutated $B R A F$. The probe was able to detect mutated $B R A F$ at the concentration of $500 \mathrm{pM}$ but normal $B R A F$ at a 50 -fold higher concentration. As the total RNA needed for the assay is only $20 \mathrm{ng} / \mu \mathrm{L}$, no polymerase chain reaction (PCR) was needed for the assay.

Dendrimers have been used for monitoring metastasized melanoma. A recent study attempted to make a dendrimer decorated with arginine-glycine-aspartic acid and fluorescence. ${ }^{114}$ It was expected that the nanoparticle would accumulate in the tumor and then be viewed through fluorescence or nuclear magnetic resonance (NMR) spectroscopy so that the tumor size and vascular structure could be detected. However, it was found that the particles accumulated in the kidney and reticuloendothelial system. Further study is needed to achieve the goal of using dendrimers for the diagnosis of metastasized melanoma.

\section{Theranostic nanomedicine in melanoma}

Recently, theranostic nanomedicine has been developed, which uses nanoparticles for both diagnosis and treatment. ${ }^{115,116}$ By employing the capacity of nanoparticles to deliver multiple agents in a single nanoparticle, imaging agents are incorporated into the nanoparticles so that the action of the therapeutic agents can be monitored in a real-time fashion. This could help to assess drug distribution and release or to evaluate drug response and efficacy. The information can also be useful for researchers, to guide the formulation of new nanoparticles with desired distribution characteristics. At present the most commonly used nanoparticles for theranostic purpose are liposomes and polymersomes. Imaging agents for magnetic resonance imaging (MRI), radionuclide imaging, and fluorescence imaging have been studied.

Theranostic nanomedicine has already been applied in melanoma study. ${ }^{117}$ Vannucci et al constructed a nanoparticle based on the heavy chain of the human protein ferritin to test in melanoma. ${ }^{42}$ The nanoparticle was loaded with $\alpha$-melanocyte stimulating hormone to specifically target melanoma, coated with PEG molecules to prevent binding to its physiological receptors, and loaded with the fluorescent reagent rhodamine for the purpose of imaging. The nanoparticle was demonstrated by confocal microscopy to bind specifically to melanoma cells rather than to colon cancer cells. For nanotheranostics, Ma et al used a lipid-based nanomicelle to deliver docetaxel. ${ }^{118}$ A fluorescent dye DiR (1,1'-dioctadecyl-3,3,3',3'-tetramethyl indotricarbocyanine iodide) was coated on the hydrophobic core of micelles to detect the distribution of the nanoparticle. The formulation of these imaging agents as nanoparticles has facilitated the examination of their distribution in tumor cells and pharmacokinetic profiling. Further studies are warrant to enable their use for clinical application.

\section{The application of nanotechnology in the establishment of metastasis models}

Metastasis is the main reason for death due to cancer. Therefore, it is necessary to understand the biology of melanoma metastasis in order to provide better approaches for its treatment. It has been recognized that metastasis is not a passive process. ${ }^{119-121}$ Cancer cells need to undergo many alterations to pass barriers, such as anoikis, to reach destination and colonization. The process of metastasis is complicated by the control of intracellular signaling pathways. ${ }^{122}$ Understanding the process will facilitate treatment to stop the metastasis. In melanoma, the most common metastatic sites are brain, liver, lung, bone, and the gastrointestinal tract. ${ }^{123}$ Brain metastasis is one of the major reasons for melanoma-caused deaths because the blood-brain barrier reduces treatment efficacy. An animal model has been established to mimic the metastasis of melanoma to the brain, and nanotechnology has been used to improve the model. ${ }^{123}$

At present, the model is made by injecting melanoma cells directly into the left cardiac ventricle to bring the cells to brain. ${ }^{124}$ The model has been used to study the role of growth factor-induced signaling pathways in metastasis, and treatment efficacy. ${ }^{70,71,124}$ However, these models are not well established, and reproducibility is poor. Nanotechnology has been used to track the injected cells. ${ }^{125}$ Melanoma cells were labeled with superparamagnetic iron oxide nanoparticles and visualized by MRI. This technique contributes to the establishment of a reproducible and predictable metastasis model and could be useful for the prediction of therapeutic outcomes.

\section{Future directions}

Acquired drug resistance to BRAF-inhibitors is a major issue in the treatment of melanoma. For example, the initial response to vemurafenib is $80 \%$, but the majority of patients will develop drug resistance. The mechanisms for such resistance could be diverse, including the overexpression of P-gp, increased drug metabolism, enhanced self-repairing ability, altered drug targets, and the activation of intracellular 
signaling pathways. ${ }^{126}$ The use of nanotechnology in dealing with this issue could be helpful but is still challenging. So far, not many studies have been done to employ nanotechnology to overcome drug resistance. Khdair et al created a single multidrug nanoparticle with both chemotherapeutic and PDT agents that would target melanoma cells, in order to overcome acquired drug resistance. ${ }^{127}$ Tran et al used a nanoparticle with both sorafenib and ceramide to prevent acquired drug resistance. ${ }^{128}$ However, the mechanisms for acquired drug resistance in melanoma have been shown to be diverse. The use of different drugs in nanoparticles will be needed depending on the mechanisms of acquired drug resistance.

Evaluation and the avoidance of severe side effects caused by nanoparticles could be critical for the successful clinical application of nanoparticles for drug delivery. Cytotoxicity to normal cells in relation to nanoparticles could be caused by size-related toxicity and the leaching of components. ${ }^{129}$ Large-size nanoparticles can accumulate in the endoplasmic reticulum system. Further, the immunogenicity of nanoparticles can cause autoimmunity. Many different types of nanoparticles have been tested; each may have different side effects, and some side effects caused by nanoparticles may be fatal. ${ }^{129}$ However, overall, the side effects of nanoparticles are not very well understood at present, and many more studies are needed.

\section{Conclusion}

Metastatic melanoma is still a difficult disease to treat. The key for improving the treatment efficacy is to have a better understanding of the pathogenesis of the disease, early diagnosis and identification of individual molecular typing, as well as novel and effective drug delivery systems. Nanotechnology has offered the potential to improve the diagnosis and treatment of melanoma. It has been demonstrated that nanoparticle-delivered anticancer drugs concentrate in tumor tissue and thus increase treatment efficacy and reduce side effects. Nanoparticles have also been shown to carry imaging agents to detect melanoma and BRAF mutation. Further studies are needed to avoid the side effects caused by some nanoparticles so that they can be applied clinically.

\section{Disclosure}

The authors report no conflicts of interest in this work.

\section{References}

1. Siegel R, DeSantis C, Virgo K, et al. Cancer treatment and survivorship statistics, 2012. CA Cancer J Clin. 2012;62(4):220-241.
2. Siegel R, Naishadham D, Jemal A. Cancer statistics, 2012. CA Cancer J Clin. 2012;62(1):10-29.

3. Jerant AF, Johnson JT, Sheridan CD, Caffrey TJ. Early detection and treatment of skin cancer. Am Fam Physician. 2000;62(2):357-368.

4. American Cancer Society [homepage on the Internet]. Skin cancer facts. Available from: http://www.cancer.org/cancer/cancercauses/ sunanduvexposure/skin-cancer-facts. Accessed June 5, 2013.

5. Zitelli JA, Mohs FE, Larson P, Snow S. Mohs micrographic surgery for melanoma. Dermatol Clin. 1989;7(4):833-843.

6. Boyle GM. Therapy for metastatic melanoma: an overview and update. Expert Rev Anticancer Ther. 2011;11(5):725-737.

7. Katipamula R, Markovic SN. Emerging therapies for melanoma. Expert Rev Anticancer Ther. 2008;8(4):553-560.

8. Khan KH, Goody RB, Hameed H, Jalil A, Coyle VM, McAleer JJ. Metastatic melanoma: a regional review and future directions. Tumori. 2012;98(5):575-580.

9. Eigentler TK, Caroli UM, Radny P, Garbe C. Palliative therapy of disseminated malignant melanoma: a systematic review of 41 randomised clinical trials. Lancet Oncol. 2003;4(12):748-759.

10. Serrone L, Zeuli M, Sega FM, Cognetti F. Dacarbazine-based chemotherapy for metastatic melanoma: thirty-year experience overview. J Exp Clin Cancer Res. 2000;19(1):21-34.

11. Brose MS, Volpe P, Feldman M, et al. BRAF and RAS mutations in human lung cancer and melanoma. Cancer Res. 2002;62(23):6997-7000.

12. Davies H, Bignell GR, Cox C, et al. Mutations of the BRAF gene in human cancer. Nature. 2002;417(6892):949-954.

13. Falkson CI, Ibrahim J, Kirkwood JM, Coates AS, Atkins MB, Blum RH. Phase III trial of dacarbazine versus dacarbazine with interferon alpha- $2 b$ versus dacarbazine with tamoxifen versus dacarbazine with interferon alpha- $2 \mathrm{~b}$ and tamoxifen in patients with metastatic malignant melanoma: an Eastern Cooperative Oncology Group study. J Clin Oncol. 1998;16(5):1743-1751.

14. Atkins MB, Hsu J, Lee S, et al; Eastern Cooperative Oncology Group. Phase III trial comparing concurrent biochemotherapy with cisplatin, vinblastine, dacarbazine, interleukin- 2 , and interferon alfa- $2 \mathrm{~b}$ with cisplatin, vinblastine, and dacarbazine alone in patients with metastatic malignant melanoma (E3695): a trial coordinated by the Eastern Cooperative Oncology Group. J Clin Oncol. 2008;26(35):5748-5754.

15. Sharma A, Sharma AK, Madhunapantula SV, et al. Targeting Akt3 signaling in malignant melanoma using isoselenocyanates. Clin Cancer Res. 2009;15(5):1674-1685.

16. Bei D, Meng J, Youan BB. Engineering nanomedicines for improved melanoma therapy: progress and promises. Nanomedicine (Lond). 2010;5(9):1385-1399.

17. Pacheco I, Buzea C, Tron V. Towards new therapeutic approaches for malignant melanoma. Expert Rev Mol Med. 2011;13:e33.

18. Tran MA, Watts RJ, Robertson GP. Use of liposomes as drug delivery vehicles for treatment of melanoma. Pigment Cell Melanoma Res. 2009;22(4):388-399.

19. Langer R. Drug delivery and targeting. Nature. 1998;392(6679 Suppl): S5-S10.

20. Duncan R. The dawning era of polymer therapeutics. Nat Rev Drug Discov. 2003;2(5):347-360.

21. Prabhakar U, Maeda H, Jain RK, et al. Challenges and key considerations of the enhanced permeability and retention effect for nanomedicine drug delivery in oncology. Cancer Res. 2013;73(8):2412-2417.

22. Gabizon A, Catane R, Uziely B, et al. Prolonged circulation time and enhanced accumulation in malignant exudates of doxorubicin encapsulated in polyethylene-glycol coated liposomes. Cancer Res. 1994;54(4): 987-992.

23. Moghimi SM, Hunter AC. Capture of stealth nanoparticles by the body's defences. Crit Rev Ther Drug Carrier Syst. 2001;18(6):527-550.

24. Prabhu P, Patravale V. The upcoming field of theranostic nanomedicine: an overview. J Biomed Nanotechnol. 2012;8(6): 859-882.

25. Sharifi S, Behzadi S, Laurent S, Forrest ML, Stroeve P, Mahmoudi M. Toxicity of nanomaterials. Chem Soc Rev. 2012;41(6):2323-2343. 
26. Liao J, Wang C, Wang Y, Luo F, Qian Z. Recent advances in formation, properties, and applications of polymersomes. Curr Pharm Des. 2012; 18(23):3432-3441.

27. Bangham AD. A correlation between surface charge and coagulant action of phospholipids. Nature. 1961;192:1197-1198.

28. Olson F, Hunt CA, Szoka FC, Vail WJ, Papahadjopoulos D. Preparation of liposomes of defined size distribution by extrusion through polycarbonate membranes. Biochim Biophys Acta. 1979;557(1):9-23.

29. Sawant RR, Torchilin VP. Challenges in development of targeted liposomal therapeutics. Aaps J. 2012;14(2):303-315.

30. Al-Jamal WT, Al-Jamal KT, Bomans PH, Frederik PM, Kostarelos K. Functionalized-quantum-dot-liposome hybrids as multimodal nanoparticles for cancer. Small. 2008;4(9):1406-1415.

31. Pearson RM, Sunoqrot S, Hsu HJ, Bae JW, Hong S. Dendritic nanoparticles: the next generation of nanocarriers? Ther Deliv. 2012;3(8): 941-959.

32. Schilrreff P, Mundiña-Weilenmann C, Romero EL, Morilla MJ. Selective cytotoxicity of PAMAM G5 core-PAMAM G2.5 shell tecto-dendrimers on melanoma cells. Int J Nanomedicine. 2012;7:4121-4133.

33. Rastogi R, Anand S, Koul V. Flexible polymerosomes - an alternative vehicle for topical delivery. Colloids Surf B Biointerfaces. 2009;72(1): 161-166.

34. Discher BM, Won YY, Ege DS, et al. Polymersomes: tough vesicles made from diblock copolymers. Science. 1999;284(5417):1143-1146.

35. Christian DA, Cai S, Bowen DM, Kim Y, Pajerowski JD, Discher DE. Polymersome carriers: from self-assembly to siRNA and protein therapeutics. Eur J Pharm Biopharm. 2009;71(3):463-474.

36. Pegoraro C, Cecchin D, Gracia LS, et al. Enhanced drug delivery to melanoma cells using PMPC-PDPA polymersomes. Cancer Lett. Epub February 10, 2013.

37. Anilkumar P, Lu F, Cao L, et al. Fullerenes for applications in biology and medicine. Curr Med Chem. 2011;18(14):2045-2059.

38. Chaudhuri P, Soni S, Sengupta S. Single-walled carbon nanotubeconjugated chemotherapy exhibits increased therapeutic index in melanoma. Nanotechnology. 2010;21(2):025102.

39. Yu M, Jambhrunkar S, Thorn P, Chen J, Gu W, Yu C. Hyaluronic acid modified mesoporous silica nanoparticles for targeted drug delivery to CD44-overexpressing cancer cells. Nanoscale. 2013;5(1):178-183.

40. Oh JM, Park DH, Choi SJ, Choy JH. LDH nanocontainers as bioreservoirs and drug delivery carriers. Recent Pat Nanotechnol. 2012;6(3): 200-217.

41. Li A, Qin L, Wang W, et al. The use of layered double hydroxides as DNA vaccine delivery vector for enhancement of anti-melanoma immune response. Biomaterials. 2011;32(2):469-477.

42. Vannucci L, Falvo E, Fornara M, et al. Selective targeting of melanoma by PEG-masked protein-based multifunctional nanoparticles. Int $J$ Nanomedicine. 2012;7:1489-1509.

43. Vader P, Fens MH, Sachini N, et al. Taxol(®)-induced phosphatidylserine exposure and microvesicle formation in red blood cells is mediated by its vehicle Cremophor(®) EL. Nanomedicine (Lond). Epub February 5, 2013.

44. Montana M, Ducros C, Verhaeghe P, Terme T, Vanelle P, Rathelot P. Albumin-bound paclitaxel: the benefit of this new formulation in the treatment of various cancers. $J$ Chemother. 2011;23(2): 59-66.

45. Hersh EM, O'Day SJ, Ribas A, et al. A phase 2 clinical trial of nabpaclitaxel in previously treated and chemotherapy-naive patients with metastatic melanoma. Cancer. 2010;116(1):155-163.

46. Feng Z, Zhao G, Yu L, Gough D, Howell SB. Preclinical efficacy studies of a novel nanoparticle-based formulation of paclitaxel that out-performs Abraxane. Cancer Chemother Pharmacol. 2010;65(5): 923-930.

47. Vanneman M, Dranoff G. Combining immunotherapy and targeted therapies in cancer treatment. Nat Rev Cancer. 2012;12(4):237-251.

48. Zhang X, Chibli H, Kong D, Nadeau J. Comparative cytotoxicity of gold-doxorubicin and InP-doxorubicin conjugates. Nanotechnology. 2012;23(27):275103.
49. Lo Prete AC, Maria DA, Rodrigues DG, Valduga CJ, Ibañez OC, Maranhão RC. Evaluation in melanoma-bearing mice of an etoposide derivative associated to a cholesterol-rich nano-emulsion. J Pharm Pharmacol. 2006;58(6):801-808.

50. Ndinguri MW, Zheleznyak A, Lauer JL, Anderson CJ, Fields GB. Application of collagen-model triple-helical peptide-amphiphiles for CD44-Targeted drug delivery systems. J Drug Deliv. 2012;2012: 592602.

51. Kottschade LA, Suman VJ, Amatruda T 3rd, et al. A phase II trial of nab-paclitaxel (ABI-007) and carboplatin in patients with unresectable stage IV melanoma: a North Central Cancer Treatment Group Study, N057E(1). Cancer. 2011;117(8):1704-1710.

52. Kottschade LA, Suman VJ, Perez DG, et al. A randomized phase 2 study of temozolomide and bevacizumab or nab-paclitaxel, carboplatin, and bevacizumab in patients with unresectable stage IV melanoma: a North Central Cancer Treatment Group study, N0775. Cancer. 2013;119(3):586-592.

53. Ott PA, Chang J, Madden K, et al. Oblimersen in combination with temozolomide and albumin-bound paclitaxel in patients with advanced melanoma: a phase I trial. Cancer Chemother Pharmacol. 2013;71(1):183-191.

54. Chen J. Targeted therapy of obesity-associated colon cancer. Transl Gastrointest Cancer. 2012;1(1):44-57.

55. Inamdar GS, Madhunapantula SV, Robertson GP. Targeting the MAPK pathway in melanoma: why some approaches succeed and other fail. Biochemical Pharmacol. 2010;80(5):624-637.

56. Chen J, Huang XF, Qiao L, Katsifis A. Insulin caused drug resistance to oxaliplatin in colon cancer cell line HT29. J Gastrointest Oncol. 2011;2:27-33

57. Li Y, South T, Han M, Chen J, Wang R, Huang XF. High-fat diet decreases tyrosine hydroxylase mRNA expression irrespective of obesity susceptibility in mice. Brain Res. 2009;1268:181-189.

58. Chen J. Multiple signal pathways in obesity-associated cancer. Obes Rev. 2011;12(12):1063-1070.

59. Chen J, Wang MB. The roles of miRNA-143 in colon cancer and therapeutic implications. Transl Gastrointest Cancer. 2012;1(2): 169-174.

60. Chen J. Prevention of obesity-associated colon cancer by (-)-epigallocatechin-3 gallate and curcumin. Transl Gastrointest Cancer. 2012;1(3):243-249.

61. Dhomen N, Da Rocha Dias S, Hayward R, et al. Inducible expression of (V600E) Braf using tyrosinase-driven Cre recombinase results in embryonic lethality. Pigment Cell Melanoma Res. 2010;23(1):112-120.

62. Dhomen N, Reis-Filho JS, da Rocha Dias S, et al. Oncogenic Braf induces melanocyte senescence and melanoma in mice. Cancer Cell. 2009;15(4):294-303.

63. Maldonado JL, Fridlyand J, Patel H, et al. Determinants of BRAF mutations in primary melanomas. $J$ Natl Cancer Inst. 2003;95(24): 1878-1890.

64. Cheung M, Sharma A, Madhunapantula SV, Robertson GP. Akt3 and mutant V600E B-Raf cooperate to promote early melanoma development. Cancer Res. 2008;68(9):3429-3439.

65. Chen J, McMillan N, Gu W. Intra-tumor injection of lentiviral-vector delivered shRNA targeting human papillomavirus E6 and E7 oncogenes reduces tumor growth in a xenograft cervical cancer model in mice. Journal of Solid Tumors. 2012;2(4):4-10.

66. Meier F, Busch S, Lasithiotakis K, et al. Combined targeting of MAPK and AKT signalling pathways is a promising strategy for melanoma treatment. Br J Dermatol. 2007;156(6):1204-1213.

67. Basu S, Harfouche R, Soni S, Chimote G, Mashelkar RA, Sengupta S. Nanoparticle-mediated targeting of MAPK signaling predisposes tumor to chemotherapy. Proc Natl Acad Sci U S A. 2009;106(19): 7957-7961.

68. Yang Y, Liu X, Zhang D, et al. Chitosan/VEGF-sIRNA nanoparticle for gene silencing. J Control Release. 2011;152 Suppl 1:e160-e161.

69. Yin D, LiY, Lin H, et al. Functional graphene oxide as a plasmid-based Stat3 siRNA carrier inhibits mouse malignant melanoma growth in vivo. Nanotechnology. 2013;24(10):105102. 
70. Xie TX, Huang FJ, Aldape KD, et al. Activation of stat 3 in human melanoma promotes brain metastasis. Cancer Res. 2006;66(6):3188-3196.

71. Kong LY, Gelbard A, Wei J, et al. Inhibition of p-STAT3 enhances IFNalpha efficacy against metastatic melanoma in a murine model. Clin Cancer Res. 2010;16(9):2550-2561.

72. Chen Y, Bathula SR, Yang Q, Huang L. Targeted nanoparticles deliver siRNA to melanoma. J Invest Dermatol. 2010;130(12):2790-2798.

73. Tran MA, Gowda R, SharmaA, et al. Targeting V600EB-RafandAkt 3 using nanoliposomal-small interfering RNA inhibits cutaneous melanocytic lesion development. Cancer Res. 2008;68(18):7638-7649.

74. Hocker TL, Singh MK, Tsao H. Melanoma genetics and therapeutic approaches in the 21st century: moving from the benchside to the bedside. J Invest Dermatol. 2008;128(11):2575-2595.

75. Hersey $\mathrm{P}$, Zhang XD. Treatment combinations targeting apoptosis to improve immunotherapy of melanoma. Cancer Immunol Immunother. 2009;58(11):1749-1759.

76. Reuland SN, Goldstein NB, Partyka KA, et al. ABT-737 synergizes with Bortezomib to kill melanoma cells. Biol Open. 2012;1(2):92-100.

77. Benimetskaya L, Ayyanar K, Kornblum N, et al. Bcl-2 protein in 518A2 melanoma cells in vivo and in vitro. Clin Cancer Res. 2006; 12(16):4940-4948.

78. Bedikian AY, Millward M, Pehamberger H, et al. Bcl-2 antisense (oblimersen sodium) plus dacarbazine in patients with advanced melanoma: the Oblimersen Melanoma Study Group. J Clin Oncol. 2006;24(29):4738-4745.

79. Beloor J, Choi CS, Nam HY, et al. Arginine-engrafted biodegradable polymer for the systemic delivery of therapeutic siRNA. Biomaterials. 2012;33(5):1640-1650.

80. Poust JC, Woolery JE, Green MR. Management of toxicities associated with high-dose interleukin-2 and biochemotherapy. Anticancer Drugs. 2013;24(1):1-13.

81. Keilholz U, Eggermont AM. The role of interleukin-2 in the management of stage IV melanoma: the EORTC melanoma cooperative group program. Cancer J Sci Am. 2000;6 Suppl 1:S99-S103.

82. Jha G, Miller JS, Curtsinger JM, Zhang Y, Mescher MF, Dudek AZ. Randomized Phase II study of IL-2 with or without an allogeneic large multivalent immunogen vaccine for the treatment of stage IV melanoma. Am J Clin Oncol. Epub December 13, 2012

83. Schadendorf D, Vaubel J, Livingstone E, Zimmer L. Advances and perspectives in immunotherapy of melanoma. Ann Oncol. 2012; 23 Suppl 10:x104-x108.

84. Mackiewicz-Wysocka M, Zolnierek J, Wysocki PJ. New therapeutic options in systemic treatment of advanced cutaneous melanoma. Expert Opin Investig Drugs. 2013;22(2):181-190.

85. Zhang Z, Tongchusak S, Mizukami Y, et al. Induction of anti-tumor cytotoxic T cell responses through PLGA-nanoparticle mediated antigen delivery. Biomaterials. 2011;32(14):3666-3678.

86. Perche F, Benvegnu T, Berchel M, et al. Enhancement of dendritic cells transfection in vivo and of vaccination against B16F10 melanoma with mannosylated histidylated lipopolyplexes loaded with tumor antigen messenger RNA. Nanomedicine. 2011;7(4):445-453.

87. Yao H, Ng SS, Huo LF, et al. Effective melanoma immunotherapy with interleukin-2 delivered by a novel polymeric nanoparticle. Mol Cancer Ther. 2011;10(6):1082-1092.

88. He H, Grignol V, Karpa V, et al. Use of a nanoporous biodegradable miniature device to regulate cytokine release for cancer treatment. J Control Release. 2011;151(3):239-245.

89. Speiser DE, Schwarz K, Baumgaertner P, et al. Memory and effector CD8 T-cell responses after nanoparticle vaccination of melanoma patients. J Immunother. 2010;33(8):848-858.

90. Stone GW, Barzee S, Snarsky V, et al. Nanoparticle-delivered multimeric soluble CD40L DNA combined with Toll-Like Receptor agonists as a treatment for melanoma. PLoS One. 2009;4(10):e7334.

91. Goldinger SM, Dummer R, Baumgaertner P, et al. Nano-particle vaccination combined with TLR-7 and -9 ligands triggers memory and effector CD8(+) T-cell responses in melanoma patients. Eur J Immunol. 2012;42(11):3049-3061.
92. Baldea I, Filip AG. Photodynamic therapy in melanoma - an update. J Physiol Pharmacol. 2012;63(2):109-118.

93. Camerin M, Magaraggia M, Soncin M, et al. The in vivo efficacy of phthalocyanine-nanoparticle conjugates for the photodynamic therapy of amelanotic melanoma. Eur J Cancer. 2010;46(10):1910-1918.

94. Idris NM, Gnanasammandhan MK, Zhang J, Ho PC, Mahendran R, Zhang Y. In vivo photodynamic therapy using upconversion nanoparticles as remote-controlled nanotransducers. Nat Med. 2012; 18(10):1580-1585.

95. Sato M, Yamashita T, Ohkura M, et al. N-propionyl-cysteaminylphenol-magnetite conjugate (NPrCAP/M) is a nanoparticle for the targeted growth suppression of melanoma cells. J Invest Dermatol. 2009;129(9): 2233-2241.

96. de Souza FF, dos Santos MC, dos Passos DC, Lima EC, Guillo LA. Curcumin associated magnetite nanoparticles inhibit in vitro melanoma cell growth. J Nanosci Nanotechnol. 2011;11(9):7603-7610.

97. Chen J, Raymond K. Roles of rifampicin in drug-drug interactions: underlying molecular mechanisms involving the nuclear pregnane $\mathrm{X}$ receptor. Ann Clin Microbiol Antimicrob. 2006;5:3.

98. Chen J, Raymond K. Nuclear receptors, bile-acid detoxification, and cholestasis. Lancet. 2006;367(9509):454-456.

99. Dong X, Mattingly CA, Tseng MT, et al. Doxorubicin and paclitaxelloaded lipid-based nanoparticles overcome multidrug resistance by inhibiting P-glycoprotein and depleting ATP. Cancer Res. 2009;69(9): 3918-3926.

100. Meng H, Mai WX, Zhang H, et al. Codelivery of an optimal drug/ siRNA combination using mesoporous silica nanoparticles to overcome drug resistance in breast cancer in vitro and in vivo. $A C S$ Nano. 2013;7(2):994-1005.

101. Ahlgrimm-Siess V, Laimer M, Arzberger E, Hofmann-Wellenhof R. New diagnostics for melanoma detection: from artificial intelligence to RNA microarrays. Future Oncol. 2012;8(7):819-827.

102. Ferris LK, Harris RJ. New diagnostic aids for melanoma. Dermatol Clin. 2012;30(3):535-545.

103. Cooper C, Sorrell J, Gerami P. Update in molecular diagnostics in melanocytic neoplasms. Adv Anat Pathol. 2012;19(6):410-416.

104. Joyce CW, Murphy IG, Rafferty M, Ryan D, McDermott EW, Gallagher WM. Tumor profiling using protein biomarker panels in malignant melanoma: application of tissue microarrays and beyond. Expert Rev Proteomics. 2012;9(4):415-423.

105. Michalet X, Pinaud FF, Bentolila LA, et al. Quantum dots for live cells, in vivo imaging, and diagnostics. Science. 2005;307(5709):538-544.

106. Kim MJ, Lee JY, Nehrbass U, Song R, Choi Y. Detection of melanoma using antibody-conjugated quantum dots in a coculture model for highthroughput screening system. Analyst. 2012;137(6):1440-1445.

107. Morosini V, Bastogne T, Frochot C, et al. Quantum dot-folic acid conjugates as potential photosensitizers in photodynamic therapy of cancer. Photochem Photobiol Sci. 2011;10(5):842-851.

108. Zheng H, Chen G, DeLouise LA, Lou Z. Detection of the cancer marker CD146 expression in melanoma cells with semiconductor quantum dot label. J Biomed Nanotechnol. 2010;6(4):303-311.

109. Fecher LA, Cummings SD, Keefe MJ, Alani RM. Toward a molecular classification of melanoma. J Clin Oncol. 2007;25(12):1606-1620.

110. Ong FS, Das K, Wang J, et al. Personalized medicine and pharmacogenetic biomarkers: progress in molecular oncology testing. Expert Rev Mol Diagn. 2012;12(6):593-602.

111. Yang H, Higgins B, Kolinsky K, et al. Antitumor activity of BRAF inhibitor vemurafenib in preclinical models of BRAF-mutant colorectal cancer. Cancer Res. 2012;72(3):779-789.

112. Bollag G, Tsai J, Zhang J, et al. Vemurafenib: the first drug approved for BRAF-mutant cancer. Nat Rev Drug Discov. 2012;11(11):873-886.

113. Huber F, Lang HP, Backmann N, Rimoldi D, Gerber CH. Direct detection of a BRAF mutation in total RNA from melanoma cells using cantilever arrays. Nat Nanotechnol. 2013;8(2):125-129.

114. Boswell CA, Eck PK, Regino CA, et al. Synthesis, characterization, and biological evaluation of integrin alphavbeta3-targeted PAMAM dendrimers. Mol Pharm. 2008;5(4):527-539. 
115. Wang LS, Chuang MC, Ho JA. Nanotheranostics - a review of recent publications. Int J Nanomedicine. 2012;7:4679-4695.

116. Luk BT, Fang RH, Zhang L. Lipid- and polymer-based nanostructures for cancer theranostics. Theranostics. 2012;2(12):1117-1126.

117. Fraix A, Kandoth N, Manet I, et al. An engineered nanoplatform for bimodal anticancer phototherapy with dual-color fluorescence detection of sensitizers. Chem Commun (Camb). 2013;49(40):4459-4461.

118. Ma M, Hao Y, Liu N, et al. A novel lipid-based nanomicelle of docetaxel: evaluation of antitumor activity and biodistribution. Int $J$ Nanomedicine. 2012;7:3389-3398.

119. Fonkem E, Uhlmann EJ, Floyd SR, et al. Melanoma brain metastasis: overview of current management and emerging targeted therapies. Expert Rev Neurother. 2012;12(10):1207-1215.

120. Scully OJ, Bay BH, Yip G, Yu Y. Breast cancer metastasis. Cancer Genomics Proteomics. 2012;9(5):311-320.

121. Trapé AP, Gonzalez-Angulo AM. Breast cancer and metastasis: on the way toward individualized therapy. Cancer Genomics Proteomics. 2012;9(5):297-310.

122. Chen J. Is Src the key to understanding metastasis and developing new treatments for colon cancer? Nat Clin Pract Gastroenterol Hepatol. 2008;5(6):306-307.
123. Cranmer LD, Trevor KT, Bandlamuri S, Hersh EM. Rodent models of brain metastasis in melanoma. Melanoma Res. 2005;15(5):325-356.

124. Kusters B, de Waal RM, Wesseling P, et al. Differential effects of vascular endothelial growth factor A isoforms in a mouse brain metastasis model of human melanoma. Cancer Res. 2003;63(17):5408-5413.

125. Sundstrøm T, Daphu I, Wendelbo I, et al. Automated tracking of nanoparticle-labeled melanoma cells improves the predictive power of a brain metastasis model. Cancer Res. 2013;73(8):2445-2456.

126. Gottesman MM. Mechanisms of cancer drug resistance. Аnnu Rev Med. 2002;53:615-627.

127. Khdair A, Handa H, Mao G, Panyam J. Nanoparticle-mediated combination chemotherapy and photodynamic therapy overcomes tumor drug resistance in vitro. Eur J Pharm Biopharm. 2009;71(2): 214-222.

128. Tran MA, Smith CD, Kester M, Robertson GP. Combining nanoliposomal ceramide with sorafenib synergistically inhibits melanoma and breast cancer cell survival to decrease tumor development. Clin Cancer Res. 2008;14(11):3571-3581.

129. Guo P, Haque F, Hallahan B, Reif R, Li H. Uniqueness, advantages, challenges, solutions, and perspectives in therapeutics applying RNA nanotechnology. Nucleic Acid Ther. 2012;22(4):226-245.
International Journal of Nanomedicine

\section{Publish your work in this journal}

The International Journal of Nanomedicine is an international, peerreviewed journal focusing on the application of nanotechnology in diagnostics, therapeutics, and drug delivery systems throughout the biomedical field. This journal is indexed on PubMed Central, MedLine, CAS, SciSearch ${ }^{\circledR}$, Current Contents ${ }^{\circledR} /$ Clinical Medicine,

\section{Dovepress}

Journal Citation Reports/Science Edition, EMBase, Scopus and the Elsevier Bibliographic databases. The manuscript management system is completely online and includes a very quick and fair peer-review system, which is all easy to use. Visit http://www.dovepress.com/ testimonials.php to read real quotes from published authors. 